\title{
An analysis of the economic and patient outcome impact of an integrated COPD service in east London
}

\author{
Anna Garner' \\ Matthew Hodson ${ }^{2}$ \\ Georgios Ketsetzis ${ }^{3}$ \\ Laurence Pulle ${ }^{3}$ \\ Janelle Yorke ${ }^{4,5}$ \\ Angshu Bhowmik ${ }^{2}$ \\ 'NHS City and Hackney Clinical \\ Commissioning Group, ${ }^{2}$ Respiratory \\ Medicine, Homerton University \\ Hospital NHS Foundation Trust, \\ ${ }^{3}$ North East London Commissioning \\ Support Unit, London, ${ }^{4}$ School \\ of Health Sciences, University of \\ Manchester, ${ }^{5}$ The Christie NHS \\ Foundation Trust, Manchester, UK
}

This article was published in the following Dove Press journal: International Journal of COPD

6 June 2017

Number of times this article has been viewed
Correspondence: Anna Garner NHS City and Hackney Clinical Commissioning Group, Third Floor A Block, St Leonards, Nuttall Street, London NI 5LZ, UK

Tel +442038163299

Email anna.garner@nhs.net
Abstract: Exacerbations of COPD carry a huge burden of morbidity and a significant economic impact. It has been shown that home care may be useful for exacerbations of COPD. This article presents a review of an integrated COPD service in east London. Hospital Episode Statistics, Public Health Mortality Files and clinical data were used to analyze differences in health care usage and COPD patient outcomes, including COPD assessment test (CAT) scores for a subsample, before and after the introduction of the integrated service. There was a significant (30\%) reduction in the number of hospital bed days for COPD patients $(P<0.05)$, alongside a significant increase in patients with only a short stay $(0-1$ days $)$ in hospital $(P<0.0001)$. There was a significant increase in the number of patients dying outside of hospital (a proxy for quality of end-of-life care) following introduction of the service $(P=0.00015)$. Patients also reported a clinically significant improvement in CAT scores. A locally developed economic model shows that the economic benefits of the service (via impact on place of death and reduction in length of hospital stay) were almost equal to the cost of the service. The increase in proportion of short-stay admissions and the reduction in bed days suggest an impact of the service on early supported discharge and that this along with an improvement in patient clinical outcomes and in quality of end-of-life care shows that an exemplar integrated COPD service can provide benefits that equate to a nearly cost-neutral service.

Keywords: COPD, commissioning, integration, health care

\section{Introduction}

Exacerbations of COPD carry a huge burden of morbidity and a significant economic impact. ${ }^{1}$ People who suffer from more frequent exacerbations ( 3 or more per year) experience a significant worsening of their quality of $\operatorname{life}^{2-4}$ and a more rapid decline in their lung function. ${ }^{5-7}$ Moreover, $\sim 31 \%$ of patients admitted to hospital for exacerbations of COPD have been found to require readmission within 90 days. ${ }^{8}$ Apart from their effects on quality of life and lung function, exacerbations also cause a financial burden on health care systems. ${ }^{9,10}$ It has been shown that intermediate care may be useful for exacerbations of COPD. ${ }^{11,12}$ Intermediate care is a multi-professional approach to looking after patients who are too unwell to care for themselves at home but potentially well enough to be out of an acute hospital bed. A specific subtype of intermediate care is hospital-at-home $(\mathrm{HaH})$, where active treatment is provided in a patient's home. ${ }^{13} \mathrm{HaH}$ comprises 2 main categories: facilitating early discharge and preventing admission into an acute hospital bed. ${ }^{14}$ Most published literature describes the process of intervening at the point of attendance at the Emergency Department and commencing $\mathrm{HaH}$ at this point as an admission avoidance pathway. ${ }^{12}$ Early discharge 
schemes (EDS) commence if the intervention is carried out after the patient has already moved from the Emergency Department to a medical bed and comprise enhanced support to patients to allow more speedy discharge from hospital and management within the community. The UK National COPD audit in 2014 showed that while the availability of EDS has increased over time, there was great variation in the availability across the UK, with nearly $20 \%$ of units not having access to one. ${ }^{15}$

The area covered by the service within this study is a highly diverse, inner-city borough in east London, with high levels of deprivation. It has been found that higher levels of deprivation are associated with higher rates of hospital admission for COPD. ${ }^{16}$ The National COPD Audit of 2003 followed by a peer review highlighted the lack of an early discharge or HaH service for COPD in the local area. The Acute COPD Early Response Service (ACERS) team was established in 2009 as an integrated COPD team with the aim of improving quality of patient care by working with primary care to improve rates of diagnosis, helping with case finding and education and providing a responsive early discharge service to patients admitted, $\mathrm{HaH}$, acute exacerbation management within the community (to prevent acute admissions and to reduce future exacerbation frequency, to improve patient quality of life) and end-of-life care service, supported by a comprehensive pulmonary rehabilitation service and a home oxygen service.

The aim of this paper is to report data from the first 3 years of this service to assess the impact it has had on outcome measures for the management of COPD in the local area. The objectives of the study were to investigate the impact of the ACERS team on:

1. Management of COPD in primary care

2. Hospital admissions due to COPD

3. Time spent in hospital for COPD admissions

4. Readmissions following discharge from hospital

5. Patient outcomes

6. Place of death for patients with COPD

7. Health care usage costs for COPD patients.

\section{Materials and methods}

\section{Service description}

The ACERS team was formed as a multi-disciplinary team of COPD specialist nurses and respiratory physiotherapists led by a nurse consultant, with medical advice and leadership provided by a respiratory consultant. The role of the team is the provision of integrated care for patients with COPD across traditional primary and secondary care boundaries. This includes management of exacerbations in an $\mathrm{HaH}$ setting, end-of-life care and education and support to primary care practitioners (around identification of undiagnosed cases of COPD and improvement in management of these patients within primary care). A total of $77 \%$ of City and Hackney general practitioner (GP) practices had staff involved in at least one ACERS engagement activity (training and education events, practice visits). The team has expanded over time, and ACERS now provides a full home oxygen service, 4 pulmonary rehabilitation groups, nurse-led clinics and a full range of intermediate care services with many referrals coming directly from patients and carers. ACERS works with all GP practices within Hackney and the City of London (the Primary Care Trust and subsequently the Clinical Commissioning Group [CCG] area) and the Homerton University Hospital.

The tender for ACERS was awarded to Homerton University Hospital in 2009. The team was fully in place in 2010. Therefore, in all analyses comparing pre-ACERS with post-ACERS, the pre-ACERS period is financial years (April to March) 2007/08-2010/11 (4 years) and the post-ACERS period is $2011 / 12-2013 / 14$ (3 years).

\section{Methods and data sources}

Data about referrals to the ACERS were obtained from their database at Homerton Hospital, and information about the patients was collected via the hospital electronic patient record (EPR) and RiO (electronic care record) systems.

Quality and outcomes framework (QOF) data were used to analyze the impact on COPD management in primary care and data from Hospital Episode Statistics (HES) ${ }^{17}$ to compare secondary care usage (including admissions, length of stay [LOS] and bed days) for COPD patients before and after the introduction of the ACERS team.

\section{Management of COPD in primary care}

QOF data on COPD management in primary care were accessed via the Health and Social Care Information Centre (obtained in 2015). ${ }^{18}$

Data on patient care plans (including care management plan [medication and other], sources of support and whom to contact in an exacerbation) and patient condition reviews in primary care were recorded on EMIS Web (in GP practices and submitted to the CCG as part of the CCG Long Term Conditions GP contract 2013/14).

\section{COPD admissions to hospital and time spent in hospital for COPD admissions}

HES data were accessed via the Capital Healthcare benchmarking consultancy CHKS portal by North East London Commissioning Support Unit (obtained in 2015). Data on 
COPD patients (primary diagnosis only) residing in the boroughs of Hackney and the City of London (City and Hackney Primary Care Trust/CCG area) were analyzed. Data on number of COPD admissions, LOS for COPD admissions and total bed days for admissions due to COPD were collected (accessed via the CHKS portal). The following 10th revision of the International Statistical Classification of Diseases and Related Health Problems codes for COPD were used: J40, J41, J42, J43 and J44. Both elective and non-elective admissions were included.

Trends in hospital admissions for COPD over time for City and Hackney patients along with other ONS London Cosmopolitan Cluster borough/CCGs (the London boroughs with most similar populations to City and Hackney: Haringey, Brent, Lambeth, Southwark, Lewisham, Newham) were compared. To account for the increasing population in City and Hackney (12\% increase between 2007/08 and 2013/14; Office for National Statistics [ONS]), we analyzed COPD admissions per 1,000 population (ONS resident population).

\section{Readmissions following discharge from hospital}

Data about readmission rates were obtained from their database at Homerton Hospital, and information about the patients was collected via the hospital EPR and RiO systems. The 30-day and 90-day readmission rates following a hospital admission for exacerbation of COPD (where COPD is recorded as the primary diagnosis for both admission and readmission) were measured.

\section{Patient outcomes from COPD}

The COPD assessment test (CAT) is a questionnaire designed to measure the impact of COPD on a person's life. ${ }^{19}$ It is made up of 8 items, each scored on a numeric scale of 0 (no impact) to 5 (very severe impact). The CAT was completed by a subset of patients prior to an ACERS nurse-led intervention (physical and holistic assessment of need including the therapeutic management of symptoms, medicines optimization including the need for nebulization, inhaler technique and any additional social support; the intervention was tailored to each patient's needs so varied in intensity and duration eg, number of visits/clinics) and post-intervention (mean number of days between scores was 48 days). All patients seen in nurse-led clinics between July 2010 and July 2011 who consented were included in the subsample.

\section{Place of death for patients with COPD}

We have used proportion of deaths from COPD that occur outside of hospital as a quantitative indicator of quality of end-of-life care. The majority of patients express a wish to die in their own home, but most deaths occur in hospital and quality of care is rated (by carers) as lowest for patients who have died in hospital. ${ }^{20-22}$ Information on place of death (categorized as in hospital or out of hospital) was obtained via the Public Health Mortality Files (accessed via City and Hackney Public Health team) for all patients residing in Hackney and the City of London (data on deaths from all causes and just deaths from COPD).

\section{Health care usage costs for COPD patients}

An economic model was developed to evaluate the cost of the ACERS team against the cost savings generated by the reduction in health care costs (further details are given in the Supplementary material).

\section{Statistical analysis}

For analysis of significance, the unpaired, 2-tailed $t$-test (Microsoft Excel) was used to compare the number (total number count for each financial year) of COPD admissions, number of COPD readmissions, and number of COPD bed days in the pre- and post-ACERS periods. The unpaired $t$-test was also used to compare the percentage of admissions that were $0-1$ day stay and the average LOS for COPD admissions (total COPD bed days divided by the total count of COPD admissions) - again, annual values for each financial year were used. Annual values were used in order to mediate any variation within the year due to seasonal effects. A $P$-value $<0.05$ was considered significant.

The Fisher's exact test was used to compare the distribution in 2 categories (number of admissions that had a $0-1$ or $\geq 2$-day LOS; place of death as hospital or non-hospital). A $P$-value $<0.05$ was considered significant.

Effect sizes (mean of difference between pre- and postACERS periods divided by the pooled estimate of standard deviation including both pre-and post-ACERS values) were calculated for all results shown to be statistically significant.

\section{Results \\ Activity of the ACERS team}

The ACERS has received just $<6,000$ referrals/patient contacts since 2011 . Nearly a third of these $(1,660)$ have been referrals for "HaH" management.

There has been a steady increase in referrals over time to the ACERS team since inception, with the ACERS team receiving $>2,000$ referrals in 2014/15 (Figure 1). The largest proportions of the referrals are for assessment, review or preventing hospital admission. 


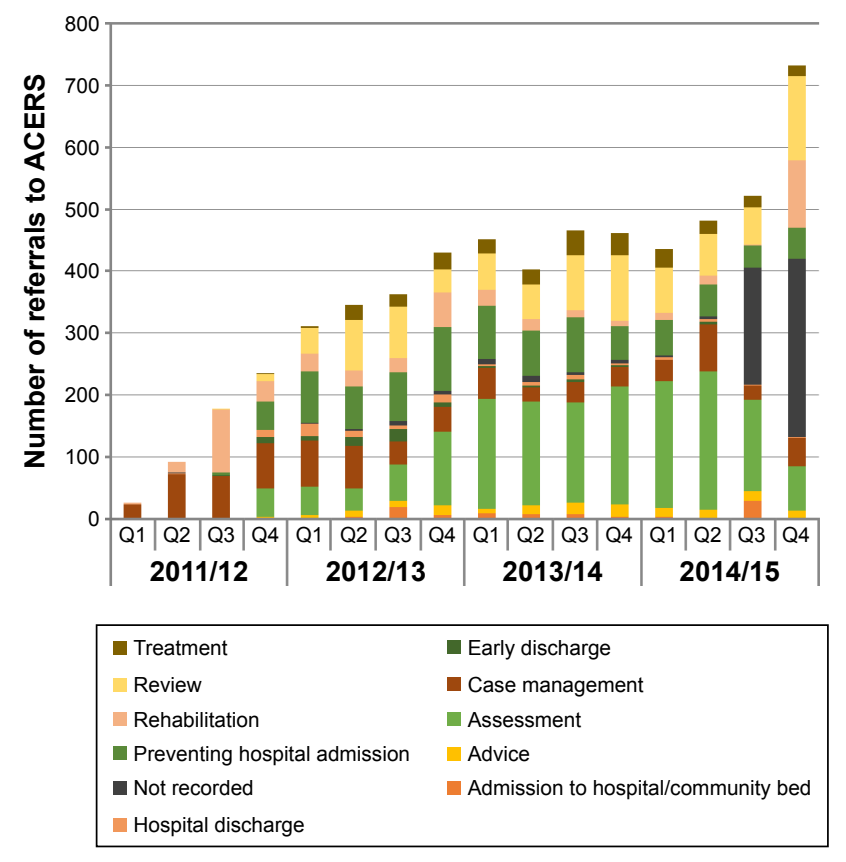

Figure I Referrals to the ACERS team.

Notes: Number and reasons for referral to the ACERS team for each quarter (QI-Q4) of financial years 201 I/ I2-2014/I5 (financial years run from April to the following March, so $201 \mathrm{I} / \mathrm{I} 2$ indicates April $201 \mathrm{I}$ to March 20I2). The total number of patients seen by the ACERS team from $2011 / 12$ to $2014 / 15$ is nearly 6,000 . The number of referrals to the ACERS team has increased over time from 450 in 20I I/I2 to 2,000 per year in 2014/I5. Data were collected from hospital electronic records and RiO. Large numbers of "not recorded" for Q3 and Q4 for 2014/I5 are due to a decrease in recording linked with changes to the RiO system (making "reason for referral" a non-mandatory field).

Abbreviation: ACERS, Acute COPD Early Response Service.

\section{Impact on management of COPD in primary care}

Analysis of QOF data for all GP practices in Hackney and the City of London shows that there has been a year-on-year increase in the number of people with a diagnosis of COPD on the GP practice QOF registers, with a faster rate of increase during 2010-2014 (post-ACERS: 6\%-8\% per year) than in previous years ( $2 \%-4 \%$ per year). In 2014 , this equates to $1.04 \%$ of the GP list population that have a COPD diagnosis (from $0.8 \%$ in 2008; shown in Table 1).

There has also been an improvement in the level of achievement for all QOF indicators relating to COPD management for City and Hackney GP practices between 2009 and 2014 (shown in Table 1), although this improvement is also linked with a commissioning incentive scheme for primary care for management of COPD. Data from the Clinical Commissioning Group Long Term Conditions GP contract (2013/14, collected by practices and submitted to $\mathrm{CCG}$ ) show that a high proportion of COPD patients $(83 \%)$ have a care plan (including care management plan [medication and other], sources of support and whom to contact in a exacerbation) and $80 \%$ of patients with severe or very severe COPD have had at least 2 reviews in the last 12 months.

Table I COPD QOF indicators for City and Hackney, London and England

\begin{tabular}{|c|c|c|c|c|c|c|c|}
\hline Indicator & 2008 & 2009 & 2010 & 2011 & 2012 & 2013 & 2014 \\
\hline Number of patients on COPD register (QOF) - City and Hackney & 2,221 & 2,267 & 2,347 & 2,499 & 2,654 & 2,871 & 2,943 \\
\hline \multicolumn{8}{|l|}{ Recorded prevalence of COPD (\% of total patient list) } \\
\hline City and Hackney & 0.8 & 0.9 & 0.9 & 0.9 & 0.9 & 1.0 & 1.03 \\
\hline London & 0.9 & 1.0 & 1.0 & 1.0 & I.I & 1.1 & I.I \\
\hline England & 1.5 & 1.5 & 1.6 & 1.6 & 1.7 & 1.7 & 1.8 \\
\hline \multicolumn{8}{|l|}{$\%$ of COPD diagnoses confirmed by spirometry } \\
\hline City and Hackney & - & 88 & 90.9 & 93.2 & 94.1 & 94.1 & 94.1 \\
\hline London & - & 89.3 & 89.4 & 88.8 & 92.5 & 91 & 90.2 \\
\hline England & - & 90.4 & 90.3 & 89.7 & 93.2 & 91.3 & 90.7 \\
\hline \multicolumn{8}{|l|}{$\%$ of COPD patients with a FEV , measurement in last 15 months } \\
\hline City and Hackney & 82.5 & 81.5 & 86.5 & 88 & 89.3 & 90 & 90.8 \\
\hline London & 84.3 & 81.1 & 87.5 & 87.8 & 88.1 & 88.1 & 86.7 \\
\hline England & 84.4 & 82.5 & 88.5 & 88.8 & 88.8 & 88.4 & 86.3 \\
\hline \multicolumn{8}{|l|}{$\%$ of COPD patients with a breathlessness assessment in last } \\
\hline \multicolumn{8}{|l|}{15 months } \\
\hline City and Hackney & - & - & 89.2 & 92.1 & 93.9 & 91.8 & 95.3 \\
\hline London & - & - & 89.7 & 91.2 & 91.4 & 91 & 90.9 \\
\hline England & - & - & 89.9 & 91.6 & 91.8 & 91.1 & 89.6 \\
\hline \multicolumn{8}{|l|}{$\%$ of COPD patients who have had flu vaccine } \\
\hline City and Hackney & 92 & 91.4 & 91.9 & 93.1 & 93 & 91.1 & 95.4 \\
\hline London & 95.2 & 91.8 & 93 & 93.1 & 93 & 91.7 & 94.7 \\
\hline England & 94 & 91.7 & 92.7 & 93.2 & 93.1 & 92.7 & 96.2 \\
\hline
\end{tabular}

Notes: -Indicator not in use for this year. Data from Primary Care Mortality Database. Available from: http://content.digital.nhs.uk/pcmdatabase. Accessed November 15, 2015. Copyright $\odot$ 2015, Re-used with the permission of the Health and Social Care Information Centre, also known as NHS Digital. All rights reserved. ${ }^{18}$

Abbreviations: QOF, quality and outcomes framework; $\mathrm{FEV}_{1}$, forced expiratory volume in I second. 


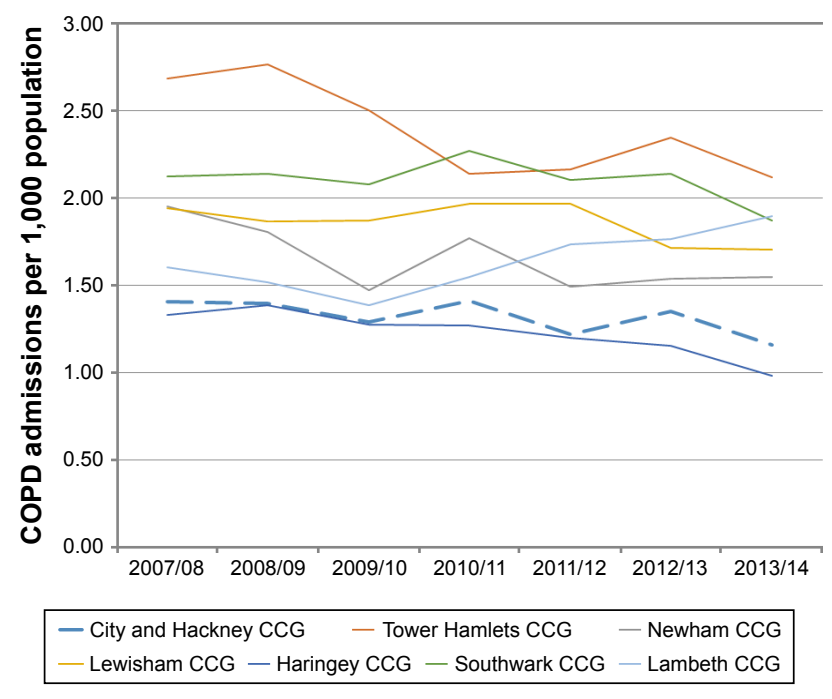

Figure 2 Rate of admissions to hospital for COPD.

Notes: The number of admissions to hospital (any trust) for London CCG areas (ONS group London Cosmopolitan) for COPD (primary reason for admission) per I,000 population (ONS resident population data) over time. Admissions have decreased in City and Hackney between 2007 and 2014. Financial years run from April to the following March, so 2007/08 indicates April 2007 to March 2008, etc. Admissions data from HES. Information on HES data available at: http://content. digital.nhs.uk/hes. Accessed April 15, 2015. Copyright (C) 2015, Re-used with the permission of the Health and Social Care Information Centre, also known as NHS Digital. All rights reserved. ${ }^{17}$

Abbreviations: CCG, Clinical Commissioning Group; ONS, Office for National Statistics; HES, Hospital Episode Statistics.

\section{Impact on COPD admissions to hospital}

Analysis of COPD admission rates (HES) for ONS group London Cosmopolitan boroughs over time shows that City and Hackney has experienced decreasing admission rates since 2010/11 (Figure 2): with an average of 1.38 admissions per 1,000 population before the establishment of ACERS (2007/08-2010/11) to 1.24 in the post-ACERS period (2011/12-2013/14) (shown in Table 2).

A total of $80 \%$ of COPD patients' admissions in City and Hackney are to the Homerton Hospital (2007/08-2013/14; HES). The ACERS team works with all patients from City and Hackney GP practices but only works with the Homerton Hospital as an acute trust $(90 \%$ of COPD admissions to the
Homerton Hospital are from City and Hackney patients [2007/08-2013/14; HES]). To further analyze the impact of the ACERS team on COPD admissions, we looked at COPD admissions for City and Hackney patients to Homerton Hospital only. The rate of admissions has decreased following the introduction of ACERS, from 1.07 admissions per 1,000 population before the introduction of ACERS to 0.99 following the establishment of ACERS (shown in Table 2), although this is not statistically significant (unpaired $t$-test, $P=0.36$ ).

\section{Impact on time spent in hospital for admissions for COPD}

To analyze whether there was any impact on patients' LOS in hospital and number of hospital bed days for COPD from the ACERS team, we again used HES data to analyze City and Hackney patients being admitted with COPD into Homerton Hospital (Figure 3).

The number of patients admitted and only having a short LOS (0-1 day) has increased over time, with the percentage of short-LOS admissions increasing from $27 \%$ in the preACERS period to $34 \%$ over the post-ACERS period (Fisher's exact test, $P<0.0001$ ) (shown in Table 2).

We also analyzed the total bed days for COPD (Figure 4). The number of bed days for COPD patients has decreased by $>30 \%$, from an average of 1,817 bed days per year in the pre-ACERS period to 1,200 per year post-ACERS (unpaired $t$-test shows significance at $P=0.048$ ) (shown in Table 2). The average LOS per patient (bed days per admission) has decreased from a mean of 6.8 days per admission to 4.5 days following the establishment of the ACERS team (unpaired $t$-test, $P=0.07$ ) (shown in Table 2).

\section{Impact on readmissions following discharge from hospital}

A total of $15.3 \%$ of patients discharged following an admission for COPD were readmitted within 30 days in the period

Table 2 Admissions and time spent in hospital for admissions for COPD

\begin{tabular}{|c|c|c|c|c|c|c|}
\hline Metric & $\begin{array}{l}\text { Pre-ACERS } \\
\text { mean value }\end{array}$ & $\begin{array}{l}\text { Post-ACERS } \\
\text { mean value }\end{array}$ & $\begin{array}{l}\text { Sample } \\
\text { size }(n)\end{array}$ & $P$-value & Change & Effect size \\
\hline $\begin{array}{l}\text { COPD admissions (City and Hackney } \\
\text { patients to all trusts) }\end{array}$ & $\begin{array}{l}1.38 \text { per } 1,000 \\
\text { population }\end{array}$ & $\begin{array}{l}\text { I.24 per I,000 } \\
\text { population }\end{array}$ & 7 & 0.13 & Nonsignificant reduction & \\
\hline $\begin{array}{l}\text { COPD admissions (City and Hackney } \\
\text { patients to the Homerton Hospital only) }\end{array}$ & $\begin{array}{l}1.07 \text { per } 1,000 \\
\text { population }\end{array}$ & $\begin{array}{l}0.99 \text { per } 1,000 \\
\text { population }\end{array}$ & 7 & 0.34 & Nonsignificant reduction & \\
\hline$\%$ of COPD admissions which are $0-1$ days & $27 \%$ & $34 \%$ & 7 & $<0.0001$ & Significant increase & 1.19 \\
\hline Average LOS for COPD admissions & 6.8 days & 4.5 days & 7 & 0.07 & Almost significant decrease & $\mathrm{I} .74$ \\
\hline Total bed days for COPD & I,8I7 per year & I,200 per year & 7 & 0.048 & Significant decrease & 2.00 \\
\hline
\end{tabular}

Abbreviations: ACERS, Acute COPD Early Response Service; LOS, length of stay. 


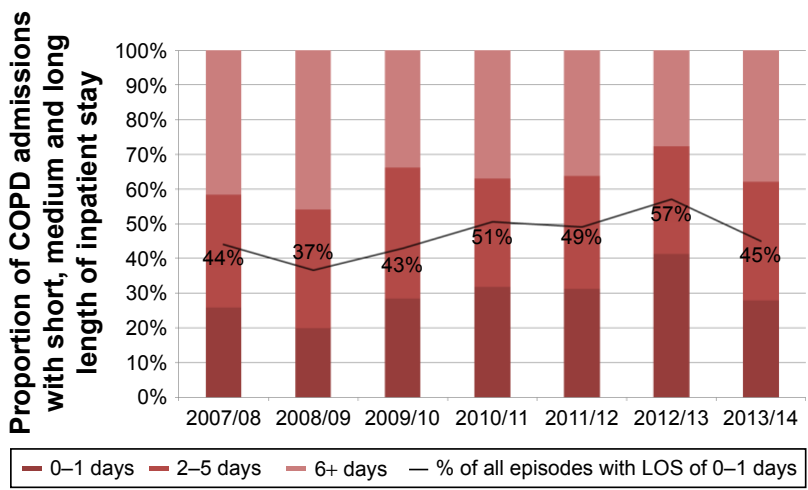

Figure 3 LOS in hospital for COPD admissions.

Notes: HES data on length of inpatient hospital stay for COPD admissions to Homerton Hospital (by City and Hackney residents only). For each period, percentage of all admissions that were short stay ( $0-1$ day), medium stay ( $2-5$ days) or long stay (6 or more days) are shown. Line shows the percentage of all episodes with an LOS that was 0 days or I day. This proportion increases over time with the introduction of the ACERS team. Financial years run from April to the following March, so 2007/08 indicates April 2007 to March 2008, etc. Data from HES. Information on HES data available at: http://content.digital.nhs.uk/hes. Accessed April 15, 2015. Copyright (C) 2015, Re-used with the permission of the Health and Social Care Information Centre, also known as NHS Digital. All rights reserved. ${ }^{17}$

Abbreviations: LOS, length of stay; HES, Hospital Episode Statistics; ACERS, Acute COPD Early Response Service.

before ACERS was in place. Following the introduction of ACERS, an average of $17.3 \%$ of patients were readmitted within 30 days. A total of $28.4 \%$ of patients were readmitted within 90 days before ACERS was in place, while 30.5\% of patients were readmitted within 90 days post-ACERS. An unpaired $t$-test gave a $P$ score of 0.51 , showing that there is no significant difference in readmission rates between the pre-ACERS and post-ACERS periods.

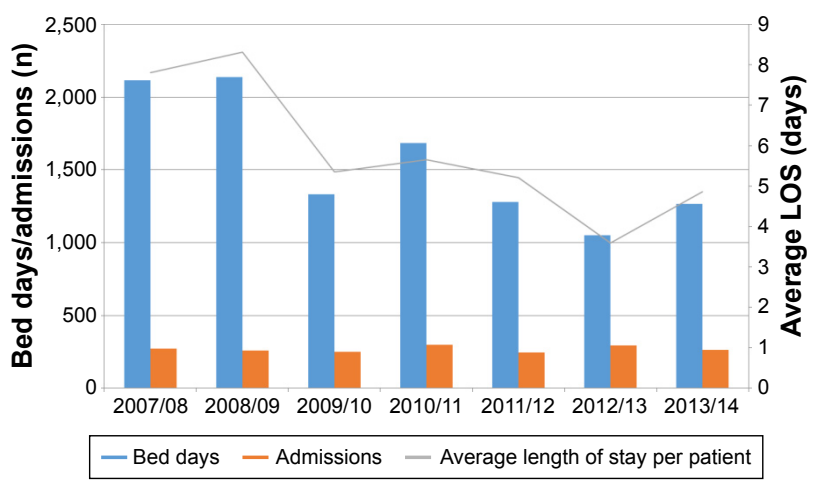

Figure 4 Hospital bed days for COPD admissions.

Notes: Total bed days spent by City and Hackney residents due to COPD admissions at the Homerton Hospital. Total bed days and number of admissions are shown for each period, along with average LOS per patient (calculated from number of bed days per admission). The total bed days have decreased between 2007 and 2014. Financial years run from April to the following March, so 2007/08 indicates April 2007 to March 2008, etc. Data from HES. Information on HES data available at: http://content.digital.nhs.uk/hes. Accessed April 15, 2015. Copyright (C) 20I5, Reused with the permission of the Health and Social Care Information Centre, also known as NHS Digital. All rights reserved. ${ }^{17}$

Abbreviations: HES, Hospital Episode Statistics; LOS, length of stay.
Impact on patient outcomes from COPD

To assess the change in COPD-related quality of life before and after intervention by the ACERS team (which included education on COPD, inhaler technique and self-management advice), CAT scores ${ }^{19}$ were measured for a sample of patients $(\mathrm{n}=69)$. The mean CAT score prior to the intervention was 24 (impact level on patient life classified as high ${ }^{23}$ ). A total of $75 \%$ of patients saw a reduction in the CAT scores post-intervention, with the mean CAT score after ACERS nurse-led case management of 20 (impact level on patient life classified as medium). The mean reduction (all patients) was 4 points, a significant reduction ( $P=0.0018$; effect size $=0.54$ ). A change in score of 2 or more suggests a clinically significant change in health status. ${ }^{23}$

\section{Impact on place of death for patients with COPD}

There has been a trend toward fewer deaths (from all causes) of City and Hackney patients in hospital over time: $64 \%$ of deaths occurring in hospital in 2007/08 reduced to $57 \%$ in 2013/14 (Figure 5). There has been a concurrent decrease in the proportion of deaths from COPD that occur in hospital over time but a sharper decrease since the introduction of the

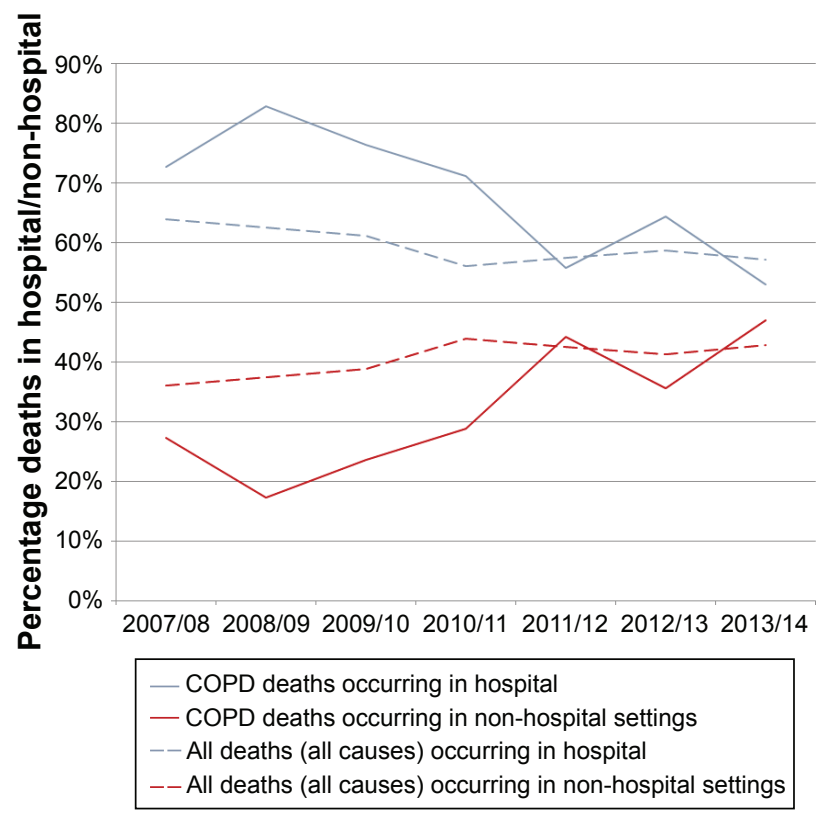

Figure 5 Place of death for deaths from COPD and all deaths.

Notes: ONS data on place of deaths for City and Hackney residents for all causes of death and deaths from COPD alone. Graph shows the proportion of deaths in hospital and out of hospital (covering home, hospice and others). The proportion of deaths occurring in hospital has decreased over time for all causes of death, but the proportion of deaths from COPD that occur in hospital has decreased at a faster rate. Financial years run from April to the following March, so 2007/08 indicates April 2007 to March 2008, etc.

Abbreviation: ONS, Office for National Statistics. 
Table 3 Percentage of deaths in hospital and out of hospital (deaths from COPD only) following the introduction of the ACERS team

\begin{tabular}{lll}
\hline Period & $\begin{array}{l}\text { Hospital deaths, } \\
\mathbf{n}(\%)\end{array}$ & $\begin{array}{l}\text { Non-hospital } \\
\text { deaths, } \mathbf{n}(\%)\end{array}$ \\
\hline Pre-ACERS & $161(76)$ & $51(24)$ \\
Post-ACERS & $104(58)$ & $76(42)$ \\
\hline
\end{tabular}

Notes: Data from Primary Care Mortality Database. Available from: http://content. digital.nhs.uk/pcmdatabase. Accessed November 15, 2015. Copyright () 2015, Reused with the permission of the Health and Social Care Information Centre, also known as NHS Digital. All rights reserved. ${ }^{18}$

Abbreviation: ACERS, Acute COPD Early Response Service.

ACERS team. The proportion of COPD deaths that occur in hospital was compared between the pre-ACERS period ( $76 \%$; shown in Table 3) and post-ACERS period (58\%) using Fisher's exact test and showed that there was a significant reduction in the proportion of COPD patients dying in hospital following the introduction of ACERS ( $P=0.00015)$.

\section{Health care usage costs for COPD patients}

An economic model (further details are given in the Supplementary material) was developed to evaluate the cost of the ACERS team against the cost savings generated by:

- The reduction in the average LOS of patients, leading to a reduction in tariff costs and a decrease in bed days $=£ 400,000$ saving per year.

- The increase in patients dying outside of hospital $=£ 252,000$ saving per year.

The CCG funded the Homerton Hospital $£ 730,500$ for the ACERS team. Adjusting for the abovementioned cost savings (a total of $\sim £ 652,000$ ), this therefore equates to a net cost of the ACERS of $£ 78,500$ in the financial year 2015/16.

\section{Discussion}

This real-world evaluation shows that an integrated COPD team can lead to an improvement in the quality of care provided to COPD patients alongside financial benefits such as shorter patient stays in hospital, reduced hospital bed days and reduced concurrent cost, with only a relatively small net cost. There was no significant reduction in the number of COPD admissions; however, this should be viewed in the context of rising admissions nationally. ${ }^{24}$ An audit conducted by the ACERS team in 2014 suggested that the majority of COPD admissions to the Homerton Hospital are from patients not known previously to the team (57\% of admissions, unpublished data) and that $10 \%$ of admissions are for patients not on any COPD treatment at all. This suggests that further work on early diagnosis and initiation of appropriate therapy is still required.
Integrated care models have been shown to be effective and reduce hospitalization and reduce the costs associated with managing COPD. ${ }^{14,25-28}$ A key aim of the ACERS was to reduce the time spent in hospital unnecessarily by COPD patients. The early supported discharge element of the service has shown a significantly reduced LOS, increased the number of patients who stay in hospital for $<1$ day and reduced hospital bed days due to COPD. The reduction in LOS was achieved in the absence of an increase in readmission rates and total bed days. Walker et al ${ }^{29}$ proposed that bed days per 1,000 population could function as a summary proxy indicator for quality of COPD care in a local area (meets the often expressed wishes of patients not be in hospital, reflects the success of primary and integrated care to reduce admissions and the success of hospitals in avoiding or shortening admissions) and variation in this metric analyzed and reported on to drive improvements in care. The current data therefore suggest that this service has improved quality of COPD care in the borough. The COPD national audit showed a decrease nationally in the average LOS for COPD patients, from an average of 5 days in 2008 and 4 days in $2014 .{ }^{24}$ The current data evidence a greater reduction locally, from 6.8 days to 4.5 days, therefore closing the gap with the average national LOS. This greater reduction could suggest that either there was greater room for improvement in this population to start with or the introduced model led to a more efficient service.

The current data did not show a reduction in the readmission rate for COPD patients following the introduction of the ACERS team. This is in keeping with previous analyses and adds further evidence that treating patients at home rather in hospital does not lead to increased risk of readmission. ${ }^{26}$ However, the fact that readmission rates did not fall could be related to the focus of the team being primarily directed toward community care. Further work is underway to try to improve the focus within the hospital to provide additional support to higher risk patients likely to be readmitted, and further analysis will reveal if this leads to a change in readmission rates.

Hernandez et $\mathrm{al}^{30}$ found that a HaH service for COPD did not lead to any significant difference in COPD-related quality of life, measured using the St George's Respiratory Questionnaire, compared to the standard hospital therapy group. However, in a subgroup of patients in this study, it was found that following case management by a member of the specialist nursing team, there was a clinically significant improvement in the impact of COPD on patient's lives (as measured by CAT scores $^{19}$ ). Scores improved from a level pre-intervention that COPD had a high impact on patients' 
lives (reduced quality of life, stopped patients completing everyday tasks, disturbed sleep and patients did not feel in control of their condition) to scores post-intervention indicating only a medium impact of COPD on their lives (some good days each week, can complete everyday activities but breathlessness slows down housework or walking, 1-2 exacerbations each year). This is likely to reflect improvements in both physical parameters (from a review of medication, appropriate additional therapies, support for smoking cessation, pulmonary rehabilitation) and emotional and social support, leading to further improvements in well-being. It has been shown that patients with end-stage COPD do not seem to be as well supported as patients with lung cancer in terms of their well-being and quality of life. ${ }^{31}$ A service such as this may help to improve this situation.

A key area of work for the ACERS team is identifying and supporting COPD patients who are approaching the end of life. The majority of patients express a wish to die in their own home. ${ }^{20}$ However, it is difficult to manage patients with increasing frequency and severity of COPD exacerbations at home and the majority of patients with respiratory disease nationally die in hospital. ${ }^{32}$ The increase in quality and patient experience from being supported to express their wishes for future care and their care delivered in accordance with these wishes should not be understated and The National Survey of Bereaved People (VOICES) shows that relatives of people who died in hospital rated overall quality of care significantly worse than any other place of death. ${ }^{20-22}$ Hence, a target of the ACERS team was to identify patients who were potentially in the last year of life and to support them to express their wishes and work with other agencies to allow death at home or in a hospice if wished. Patients were helped to access end-of-life care services (including a joint Respiratory and Palliative care clinic for COPD patients, held at St Joseph's Hospice). These steps have led to a reduction in the proportion of deaths in hospital for people with COPD. The corresponding cost saving could provide a big incentive to commissioners to implement such services.

The authors developed an economic model to weigh the costs of this service against the financial savings from reduced health care usage. The total cost savings associated with the service show that the implementation of an integrated COPD team can be nearly cost neutral. This does not take into account the quality benefits and increased patient satisfaction that can be achieved, and thus, these benefits come at little net cost to commissioners, and we would suggest that the overall benefits for patients outweigh the costs.
A particular strength of this real-world analysis is that it reflects actual care delivery conditions, and no patients who were within the catchment area of the service were excluded. Although other studies have looked at web-based interventions, lack of access or illiteracy prevented the use of such interventions in a large subgroup of patients: ${ }^{28}$ no such limitations apply to this analysis.

The main learning points from the implementation of the ACERS team are around the importance of early embedding of the service, improving pathways both in primary care (particularly around integration of ACERS with schemes in primary care to improve COPD management) and within the acute trust. Internationally, there is a drive toward more such services. By implementing an integrated COPD service with due engagement and clear pathways, significant improvements in quality of care and health economic benefits may be obtained.

\section{Databases accessed}

All databases used in this study were freely available and contained only anonymized aggregate data, with the exception of HES data. HES data were accessed via the CHKS portal, which is not freely available but only provided aggregate data with no patient-identifiable details included. Therefore, the study is excluded from the need for a NHS Research Ethics Committee review and no ethical approval was needed.

\section{Disclosure}

The authors report no conflicts of interest in this work.

\section{References}

1. Toy EL, Gallagher KF, Stanley EL, Swensen AR, Duh MS. The economic impact of exacerbations of chronic obstructive pulmonary disease and exacerbation definition: a review. COPD. 2010;7(3):214-228.

2. Seemungal TA, Donaldson GC, Paul EA, Bestall JC, Jeffries DJ, Wedzicha JA. Effect of exacerbation on quality of life in patients with chronic obstructive pulmonary disease. Am J Respir Crit Care Med. 1998;157(5 pt 1):1418-1422.

3. Solem CT, Sun SX, Sudharshan L, Macahilig C, Katyal M, Gao X. Exacerbation-related impairment of quality of life and work productivity in severe and very severe chronic obstructive pulmonary disease. Int $J$ Chron Obstruct Pulmon Dis. 2013;8:641-652.

4. Miravitlles M, Ferrer M, Pont A, et al; IMPAC Study Group. Effect of exacerbations on quality of life in patients with chronic obstructive pulmonary disease: a 2 year follow up study. Thorax. 2004;59(5): 387-395.

5. Donaldson GC, Seemungal TAR, Bhowmik A, Wedzicha JA. Relationship between exacerbation frequency and lung function decline in chronic obstructive pulmonary disease. Thorax. 2002;57(10):847-852.

6. Halpin DM, Decramer M, Celli B, Kesten S, Liu D, Tashkin DP. Exacerbation frequency and course of COPD. Int J Chron Obstruct Pulmon Dis. 2012;7:653-661.

7. Makris D, Moschandreas J, Damianaki A, et al. Exacerbations and lung function decline in COPD: new insights in current and ex-smokers. Respir Med. 2007;101(6):1305-1312. 
8. Price LC, Lowe D, Hosker HSR, et al; British Thoracic Society and the Royal College of Physicians Clinical Effectiveness Evaluation Unit (CEEu). UK National COPD Audit 2003: impact of hospital resources and organisation of care on patient outcome following admission for acute COPD exacerbation. Thorax. 2006;61(10):837-842.

9. Anzueto A. Impact of exacerbations on COPD. Eur Respir Rev. 2010; 19(116):113-118.

10. Miravitlles M, Murio C, Guerrero T, Gisbert R; DAFNE Study Group. Decisiones sobre Antibioticoterapia y Farmacoeconomía en la EPOC. Pharmacoeconomic evaluation of acute exacerbations of chronic bronchitis and COPD. Chest. 2002;121(5):1449-1455.

11. Gravil J, Al-Rawas O, Cotton M, Flanigan U, Irwin A, Stevenson R. Home treatment of exacerbations of chronic obstructive pulmonary disease by an acute respiratory assessment service. Lancet. 1998; 351(9119):1853-1855.

12. Davies L. 'Hospital at home' versus hospital care in patients with exacerbations of chronic obstructive pulmonary disease: prospective randomised controlled trial. BMJ. 2000;321(7271):1265-1268.

13. British Thoracic Society Guideline Development Group. Intermediate care - Hospital-at-Home in chronic obstructive pulmonary disease: British Thoracic Society guideline. Thorax. 2007;62(3):200-210.

14. Richards SH, Coast J, Gunnell DJ, Peters TJ, Pounsford J, Darlow MA Randomised controlled trial comparing effectiveness and acceptability of an early discharge, hospital at home scheme with acute hospital care. BMJ. 1998;316(7147):1796-1801.

15. Stone RA, Holzhauer-Barrie J, Lowe D, et al. COPD: Who cares? National Chronic Obstructive Pulmonary Disease (COPD) Audit Programme: Resources and organisation of care in acute NHS units in England and Wales 2014. National organisational audit report. London: RCP; 2014.

16. Calderón-Larrañaga A, Carney L, Soljak M, et al. Association of population and primary healthcare factors with hospital admission rates for chronic obstructive pulmonary disease in England: national cross-sectional study. Thorax. 2011;66(3):191-196.

17. NHS Digital. Hospital Episode Statistics. Information on HES data available at: http://content.digital.nhs.uk/hes. Accessed April 15, 2015.

18. NHS Digital. Health and Social Care Information Centre. Primary Care Mortality Database. Available from: http://content.digital.nhs uk/pcmdatabase. Accessed November 15, 2015.

19. Jones PW, Harding G, Berry P, Wiklund I, Chen W-H, Kline Leidy N. Development and first validation of the COPD Assessment Test. Eur Respir J. 2009;34(3):648-654.
20. Office of National Statistics. National Survey of Bereaved People (VOICES): 2014. Available from: http://www.ons.gov.uk/ons/rel/ subnational-health1/national-survey-of-bereaved-people--voices-/2014/ stb-voices-2014.html. Accessed October 17, 2015.

21. Tang ST. When death is imminent: where terminally ill patients with cancer prefer to die and why. Cancer Nurs. 2003;26(3):245-251.

22. Gomes B, Calanzani N, Gysels M, Hall S, Higginson IJ. Heterogeneity and changes in preferences for dying at home: a systematic review. BMC Palliat Care. 2013;12(1):7.

23. Jones PW, Bruselle G, Dal Negro RW, et al. Properties of the COPD assessment test in a cross-sectional European study. Eur Respir J. 2011; 38(1):29-35

24. Stone R, Holzhauer-Barrie J, Lowe D, et al. COPD: Who cares matters. National Chronic Obstructive Pulmonary Disease (COPD) Audit Programme: Clinical audit of COPD exacerbations admitted to acute units in England and Wales 2014. National clinical audit report. London: RCP; 2015.

25. Kastelik JA, Lowe D, Stone RA, Buckingham RJ, Roberts CM. National audit of supported discharge programmes for management of acute exacerbations of chronic obstructive pulmonary disease 2008. Thorax. 2012;67(4):371-373.

26. Ram FS, Wedzicha JA, Wright J, Greenstone M. Hospital at home for patients with acute exacerbations of chronic obstructive pulmonary disease: systematic review of evidence. BMJ. 2004;329(7461):315

27. Seemungal TA, Wedzicha JA. Integrated care: a new model for COPD management? Eur Respir J. 2006;28(1):4-6.

28. Casas A, Troosters T, Garcia-Aymerich J, et al; Members of the CHRONIC Project. Integrated care prevents hospitalisations for exacerbations in COPD patients. Eur Respir J. 2006;28(1):123-130.

29. Walker PP, Thompson E, Hill SL, Holton K, Bodger K, Pearson MG. Commissioning for COPD care: a new, recordable metric that supports the patient interest. J Public Health. 2015;38(2):396-402.

30. Hernandez C, Casas A, Escarrabill J, et al. Home hospitalisation of exacerbated chronic obstructive pulmonary disease patients. Eur Respir J. 2003;21(1):58-67.

31. Gore JM, Brophy CJ, Greenstone MA. How well do we care for patients with end stage chronic obstructive pulmonary disease (COPD)? A comparison of palliative care and quality of life in COPD and lung cancer. Thorax. 2000;55(12):1000-1006.

32. Public Health England. End of Life Care Intelligence Network CCG profiles: place and underlying cause of death. Available from: http:// www.endoflifecare-intelligence.org.uk/profiles/CCGs/Place_and_ Cause_of_Death/atlas.html. Accessed October 17, 2015. 


\section{Supplementary materials Economic model}

An economic model was developed to evaluate the cost of the Acute COPD Early Response Service (ACERS) team against the cost savings achieved as a result of the operation of the service. The model incorporated the patient pathway and costs and benefits accrued at hospital and out of hospital, during and after the interaction with the ACERS.

GP quality and outcomes framework data indicated the existence of 2,943 COPD registered patients in 2013-2014 in City and Hackney. We used incidence and prevalence data together with Greater London Authority population data to predict the number of COPD patients until the financial year 2020/21. Using Hospital Episode Statistics and locally available data, we estimated a number of parameters and their value up to the financial year 2020/21, including the rate of admissions in City and Hackney, the uptake rate for assisted discharge, number of deaths annually attributed to COPD, number of new referrals to ACERS, percentage of all City and Hackney admissions to the Homerton Hospital, percentage of admissions for COPD with $<1$ day of stay, percentage of COPD patients with a care plan and percentage of severe COPD patients with at least 2 reviews every 12 months. Where no local data were available, we used National Institute for Clinical Excellence or other national COPD parameter estimates to inform the model.

We used data from Secondary Uses Service to identify the number of hospital spells, the associated Healthcare Resource Group diagnosis/treatment codings and the on-cost admissions for COPD for City and Hackney patients. National tariff costs were used to establish an "average cost per admission" for different length of stay (LOS) periods and different HRGs. This was then applied to the data on change in average LOS for the pre- and post-ACERS periods to calculate the cost savings corresponding to the reduction in LOS for COPD patients following the introduction of ACERS. This gave a cost saving of $\sim £ 399,500$ for $2015 / 16$.

To calculate the savings from the increased rate of outof-hospital deaths following ACERS, the average cost per hospital death (in the last 3 months of life; £4,613) and the cost of a hospice/community managed death $(£ 424)^{1}$ were applied to the reduction in the number of deaths occurring in hospital to give a net saving of $£ 252,000$ for 2015/16.

The Clinical Commissioning Group (CCG) funded the Homerton Hospital $£ 730,500$ for the ACERS team. Adjusting for the abovementioned cost savings (a total of $\sim £ 652,000$ ) therefore equates to a net cost of the ACERS of $£ 78,500$ in the current financial year.

Using Greater London Authority population projections, the model has derived prevalence projections and used expected year-on-year tariff increases together with all the earlier data to predict both the activity and costs related to COPD demand and supply of the ACERS with a 5-year forward horizon, including expected/projected hospital activity (for different LOSs) for COPD. The model indicates that the ACERS as it operates today will bring sustainable net monetary benefits to the City and Hackney CCG from the financial year 2019-2020 onward.

\section{Reference}

1. The Nuffield Trust. Exploring the cost of care at the end of life-Marie Curie. Available from: http://www.nuffieldtrust.org.uk/publications/ exploring-cost-care-end-life. Accessed October 2015.
International Journal of COPD

\section{Publish your work in this journal}

The International Journal of COPD is an international, peer-reviewed journal of therapeutics and pharmacology focusing on concise rapid reporting of clinical studies and reviews in COPD. Special focus is given to the pathophysiological processes underlying the disease, intervention programs, patient focused education, and self management protocols.

\section{Dovepress}

This journal is indexed on PubMed Central, MedLine and CAS. The manuscript management system is completely online and includes a very quick and fair peer-review system, which is all easy to use. Visit http://www.dovepress.com/testimonials.php to read real quotes from published authors. 